\title{
NATUREZA DESUMANA: DESMESURAS DO MUNDO AO HOMEM
} INHUMAN BEING NATURE: DISCOURTESIES OF WORLD FOR THE MAN

\author{
Luis Artur Costa, Daniel Dutra e Tania Mara Galli Fonseca \\ Universidade Federal do Rio Grande do Sul, Porto Alegre, Brasil
}

\section{RESUMO}

O presente artigo propõe-se a erigir um conceito de natureza imanente e paradoxal que dê sustento às práticas da psicologia social de desnaturalização das configurações sociais. A partir da problematização da natureza em autores fundamentais da filosofia, Aristóteles e Rousseau, elabora-se uma nova concepção de natureza desnaturada e livre das amarras das representações essencialistas e totalizantes do humanismo clássico e iluminista. Afirmando outra possibilidade de homem e humanidade para além da clausura de sua própria representação ideal e analítica, o conceito de natureza aqui erigido impede o esvaziamento das práticas de desnaturalização em slogan, ao fornecer para essa prática um substrato ontoepistêmico adequado às suas desmesuras ao humano. Abre-se então a possibilidade de operar conceitos fluidos como o de subjetivação e devir ao invés do de identidade e estado.

Palavras-chave: natureza; subjetivação; diferença.

\begin{abstract}
This article proposes to build a concept of immanent and paradoxical nature that gives sustenance to the practices of the social psychology of denaturalization of social configurations. From the problematization of the nature in fundamental authors in western philosophy, Aristotle and Rousseau, a new concept of an unnatural nature is created, free from the essentialistic and totalizing representations of classical and enlightened humanism. Affirming further possibility of man and humanity beyond the closing of his/her own ideal and analytical representation, the concept of nature here erected prevent the practice of emptying in denaturalization slogan, to provide for this practice a-epistemic suitable substrate onto their disproportionate to the human. Then it opens up the possibility of operating fluid concepts such as subjectivity instead of becoming an identity and status.
\end{abstract}

Keywords: nature; subjectivity process; difference.

\section{Desnaturalizando: a construção de um método}

A psicologia se constitui como uma área de problemáticas híbridas, provocando o agenciamento entre o universo técnico, animal e humano: desde as psicologias clínicas e suas visões sobre os modos humanos de viver, passando pelos modelos de inteligência artificial e o intermezzo da psicologia comparada, até a psicologia animal propriamente dita. Tal configuração provoca diversos encontros entre as ciências ditas leves ou humanas e as consideradas pesadas ou naturais. A natureza do seu objeto tem sido fruto da constante construção de cada perspectiva. Esta heterogeneidade, muitas vezes conflitante e algumas paradoxal, permanece no escopo da Psicologia social e de suas questões, sendo até ampliada pelas diversas linhas constituintes das Ciências Sociais: área da saúde e das ciências humanas a um só tempo de modo mais intenso ainda.
No entanto, no que tange à Psicologia e, principalmente, sua vertente Social, a principal querela não está entre ciências naturais e humanas, mas antes entre as concepções de naturezas dos seus campos. Pouco diferem, nesse sentido, os que buscam as razões de um determinado modo de organização coletiva na seleção filogenética da espécie e seus instintos de massa, em reações bioquímicas neurais geneticamente determinadas ou em estruturas abstratas e universais constitutivas da subjetividade dos homens: todos estão na busca da origem ou do estado essencial de uma forma ou substância. Em busca de uma natureza na sua acepção clássica e/ ou iluminista: humanista enfim, como veremos através de Aristóteles e Rousseau. Por contraposição, existem os que querem apreender os modos de constituição, permanência e mudança das constantes variações constituintes dos heterogêneos processos de subjetivação. E esses, ainda que possam ter importantes diferenças entre si, compartilham o gosto pelo devir como natureza 
de um mundo aquém das estruturas e essências, como a análise institucional, a esquizoanálise e outras linhas atreladas à filosofia da diferença.

A problematização do conceito de natureza nos permite melhor definir uma prática frequente na Psicologia Social: a Desnaturalização, a qual opera a desconstrução de uma determinada configuração ou estado usualmente tomados como naturais, e evidenciar os artifícios envolvidos na sua construção. Trata-se de romper com uma lógica instituída demonstrando sua contingência e, por conseguinte, a possibilidade de desvio e transformação perante a mesma: a um só tempo retirar sua essencialidade e visibilizar sua construção.

No entanto, tal operação não incorre na simples negação da natureza enquanto campo problemático válido e operativo. Não se trata da mera ausência de concepção, o que empobreceria e reduziria nossa perspectiva sobre o mundo, posto que ao desnaturalizar, enquanto mera negação da natureza em si, não nos defrontamos com o problema, mas apenas o negamos em prol de outra perspectiva que não o contempla. Assim, desconstruir e desnaturalizar não são o mesmo que destruir: seria ingenuidade desvencilhar-se da tarefa de pensar a ontologia e a epistemologia de nossas práticas no tempo.

Antes, como veremos abaixo, propomos outra perspectiva de natureza mais afeita ao devir da imanência, ao invés de simplesmente esvaziar de sentido o termo. Assim, ao falarmos do mundo e do homem, já não vemos os binarismos entre mundo e homem, cultura e natura, entre outros, pois erigimos uma concepção de ontologia e epistemologia a partir da diferença, da heterogeneidade e do devir. A qual nos permite operar sobre os processos contemporâneos sem o peso do conceito de natureza naturalizado na longa história do humanismo clássico e iluminista. Assumimos, portanto, antes de tudo, um compromisso ético com o devir e a diferença. Não se trata de negar uma afirmação com o niilismo do ressentido que encerra as possibilidades do mundo; ao invés disso, propomos uma subversão, uma versão menor, que perverte a lógica instituída e afirma as possibilidades da invenção: da criação de outros modos, estilos, de ser que afirmam o novo enquanto desvio do mesmo com a leveza de quem ficciona uma vida.

\section{Da natureza: o problema}

Perguntar-se sobre a natureza das coisas é questão muito comum não só nas ciências humanas, mas também nas exatas, servindo de retórica metafísica ao substrato estilístico do pensamento. Perguntar-se sobre a natureza de si, das coisas e do mundo não é uma questão apenas. Não porque se trate de uma multitude de perspectivas parciais que inquirem uma infinidade de naturezas específicas, mas antes pela variação da natureza do próprio conceito de natureza. Desse modo, ao propormo-nos uma cartografia por sobre as naturas que habitam nosso campo psi, torna-se imprescindível, antes de tudo, desenhar as diversas variações sobre o tema da natureza mesma, em si: a natureza da natureza. Tão vasta é esta tarefa que no presente trabalho iremos nos prender apenas à desconstrução, a partir da filosofia da diferença, de duas acepções básicas do conceito de natureza: essência necessária e estado de inocência, uma concepção metafísica e outra antropológica da natureza, respectivamente. Ambas constituindo importantes questões à psicologia e psicologia social.

A primeira forma do conceito de natureza trabalharemos a partir da sua concepção aristotélica. Natureza tomada como essência necessária, ou seja, os atributos essenciais à definição do ser em sua identidade ontológica substancial. A natureza do que é seu, sobre o que lhe é natural para si, o que é a sua natureza por si. Já a segunda definição de natureza, aqui trabalhada a partir de Rousseau, fala sobre um estado original dos homens, provendo este de alguma ordem (ou desordem) que lhe é inerente em sua pureza, ou seja, sem a interferência de agentes externos a esta natura.

Tais conceitos de natureza erigem conjuntos unos que se opõem a conjuntos considerados heterogêneos e secundários. As construções de binarismos são diversas, podemos de início exemplificar três das mais comuns: natural versus artificial, natureza versus cultura e essencial versus casual. Desse modo vemos uma estreita ligação entre as variações do conceito, formando uma rica trama cerzida por alguns pontos de passagem de um ao outro. Puxando alguns fios desta rede, desfazendolhe pontos de sua trama, é que pretendemos talhar outro instrumento conceitual que nos permita capturar outras coisas além de identidades, substâncias reificadas, corpos e purezas brutas.

\section{O próprio de si em si mesmo: por uma coerência total}

A natureza, a partir dessa primeira definição, é a essência necessária dos seres que têm por si movimento, ou seja, que mudam a si sem necessidade de agentes externos a eles, entendendo por externo qualquer propriedade acidental, ou seja, tudo aquilo que não lhe é essencialmente necessário para seu ser: sua ousia, a substância do ontos. A natureza, então, é uma causa, uma necessidade inerente ao objeto. Em função disso se denomina natural ao ser que tem em si seus princípios de movimento (espacial e de crescimento) e mudança. Ao que sofre ações de agentes externos, causas acidentais, não se pode atribuir o status ôntico de natural. 
Próxima dessa definição da natureza como substancia metafísica, encontramos uma outra face do mesmo conceito. Neste ponto de vista, a natureza é tomada como matéria intrínseca, substância bruta, inerte, sem ação sobre si, preexistente aos seres para os quais provê a matéria primeira da existência física: "Como o bronze à estátua de bronze" (Aristóteles, 1945, p. 104). Nessa acepção, a natureza desempenha papel de essência e matéria primeira, mas, ao invés de categorizar-se como ação de si sobre si próprio ou causa necessária, aqui ela remete diretamente ao mundo da phisys: "La naturaleza es la esencia de las cosas materiales" (Aristóteles, 1945, p. 104).

Assim, a natureza provê aos entes as formas (causa inerente) e substâncias (matéria inerte) necessárias para sua ontologia, para o ser em si e por si: "Por tanto, la reunión de la esencia y de la matéria constituye la naturaleza de los seres". O ser é sua matéria e forma essencialmente necessárias a si, por si mesmas existentes nesse. As coisas naturais são, por natureza, em si. Já os seres acidentais dependem dos artifícios para serem, pois que não são em si e por si (em ato ou potência), antes dependem de um substrato outro, sujeito ou objeto, ao qual podem ser atribuídos como predicados. Quanto mais natural é um ente, mais ligado à sua substância, às suas essências necessárias esse o é. Pois menos submetido aos artifícios dos acidentes está. Da mesma forma, a unicidade do ente mais perfeita é a que prescinde dos acidentes e seus artifícios construídos no tempo e no acaso $^{1}$. Vemos, portanto, aqui, a estreita relação entre o natural que se opõe ao artificial e o natural que se opõe aos atributos não essenciais. Artificial é a constituição ontológica que se dá de forma não necessária, ou seja, mediante o mútuo acoplamento temporal e temporário entre os acidentes e seu sujeito ou objeto. São artifícios, ou seja, ações incorporadas a algo anterior dado como puro e necessário em si e por si. Vemos aí as claras relações entre a natureza aplicada como ferramenta identitária de captura e cristalização do sujeito, segundo uma divisão desse em essencial e acidental, e a natureza usada como ferramenta de depuração entre as coisas em natura, dadas pelo mundo em si, e as coisas feitas pelo homem neste mundo e que com esse se compõe com status ontológicos distintos.

Não há como deixar de ressaltar a evidente atribuição de uma hierarquia ontológica binária, onde o modo natural se apresenta como mais verdadeiro ou/e mais belo ou/e mais puro. A ponto de encontrarmos, no primeiro motor aristotélico, espécie de entidade primeira que a tudo criou e move, sem mover ou mudar a si, o cume do natural, do em si e por si. Não se trata evidentemente de uma doutrina dos graus de perfeição do ser como em Platão, mas contém evidentes atribuições de valor aos modos do ser: aparência (passível de falsidade e contradição) e essência (necessariamente verdadeira). Assim, vemos a dominação da representação de igualdade sobre a concretude da diferença em diversos âmbitos. A identidade essencial, diferentemente da acidental, é segura, não sujeita ao fortuito, às contradições e ao engano. Tal unidade do ser se opõe à "heterogeneidade" (Aristóteles, 1945, p.113), conceito aqui definido pela pluralidade de forma, matéria ou/e definição. A relação entre ambos será mediada por um conceito de diferença tomado em função da construção de identidades, possibilitando a operação analógica na construção de gêneros: "Diferente se dice de las cosas heterogéneas, que son idénticas desde algún punto de vista" (Aristóteles, 1945, p.113), sendo tal ponto de vista não a diferença discreta, de número, mas sim a de forma, por analogia ${ }^{2}$.

"El ser se entiende de muchas maneras, pero estos diferentes sentidos se refieren a una sola cosa, a una misma naturaleza, no habiendo entre ellos solo comunidad de nombre" (Aristóteles, 1945, p. 75). Ainda que tal afirmação pudesse ser compreendida como afirmação de um plano comum da existência, vemos aí a afirmação do Mesmo, de uma homogeneidade ontológica que por sua vez implicará uma unicidade epistêmica que tenderá para a simplificação dos seres segundo o Mesmo Generalizado.

Aristóteles dirá então, na Metafísica, que esta, a ciência das coisas essenciais, perenes, é uma ciência melhor do que a que se debruça sobre as alterações do ser. Há que se mirar para além dos movimentos aparentes e vislumbrar a plena identidade essencial. Ainda que admita a multiplicidade de formas possíveis de conhecer às coisas do mundo, Aristóteles assegurará ser mais seguro aquiescer às essências necessárias em detrimento dos acidentes e sua fugacidade inconstante. Sobre o estudo dos seres diz que "distinguimos diferentes grados de conocimiento, y décimos que tienen una ciencia más perfecta los que conocen, no sus cualidades, sus cantidades, sus modificaciones, sus actos, sino su esencia" (Aristóteles, 1945, p. 57).

\section{Desapropriando: da diluição das coisas em fluxos errantes}

Alegando a unicidade do sentido da existência das coisas e dos termos que a esta se referem, Aristóteles tece um argumento contra o paradoxo da coexistência de contrários nos sentidos da essência de um ser determinado. Afirma uma clara distinção entre o ser e o não ser, utilizando-se de silogismos básicos contra as aparências sofistas em Protágoras: "por lo conseguinte, ser hombre no puede significar lo mismo que no ser hombre, si la palabra hombre significa una naturaleza determinada, y no sólo los atributos de un objeto determinado" (Aristóteles, 1945, p.83). Admitir esta não 
unicidade dos seres específicos e seus sentidos seria negar a essência, a substância dos entes, concluindo, por fim, que existem somente os acidentes. Assim, objetos e sujeitos, a substância em si, aquilo "que nunca se predica de um sujeito, nem em um sujeito" (Aristóteles, 1985, p.48), tornar-se-iam nada mais do que predicados de si, dessubstancializando o ser em uma cadeia processual de acidentes ao modo do rio heraclitiano, ou melhor, ao modo do rio de Crátilo, onde resta apontar ao fluxo, pois nem na primeira vez que se denomina o rio esse é o mesmo, fugindo sempre da palavra tomada como representação e abrindo sua compreensão enquanto ação.

Aceitar a condição paradoxal dos seres implicaria inevitavelmente a negação da ideia de essência, pois somente os acidentes poderiam existir segundo o absurdo da coexistência do ser e do não ser segundo um mesmo conceito, posto que muitas vezes sejam fortuitos, fugazes e enganosos. Já as essências necessárias aceitam a sucessão de contrários em si (acidentes), sem, no entanto, modificarem a si mesmas nesta operação: "Agora, a principal propriedade da substância parece ser isto: que, apesar de permanecer idêntica, uma, e a mesma, é capaz de receber qualificações contrárias" (Aristóteles, 1985, p.57).

Assim, findando com a reificação em essências substanciais, o ser seria os atributos, ao invés destes atributos serem no/do ser. Como diz Aristóteles (1945) em seu exemplo, segundo uma ontologia substancialista, o branco é no homem que é branco, que possui o branco em si, mas não por si, posto que pode deixar de ser branco e continuar sendo a substancia que é. Desse modo, a brancura é no homem, mas o homem não é a brancura nem a brancura é o homem. No entanto, ao desfazermo-nos da essência e sua reificação dos processos em entes (substâncias), vemos a insurgência dos atributos como definidores da dita identidade da existência dos seres, o que implica a dissolução da identidade mesma, liberando aos fluxos de atributos per se, além e aquém de sujeitos e objetos unificadores e objetificadores da sua volatilidade. Tal profusão de acidentes gera um plano de composição comum e não uma segmentação de cada atributo em si, pois uma das consequências do abandono das essências das coisas, segundo Aristóteles (1945), é o paradoxo da identidade total: tudo é tudo. Pois, se afirmamos a veracidade de todas as afirmações, inclusive as contraditórias, teríamos que aceitar a um só tempo a afirmação e a negação do ser, tornando a todas as coisas indiferenciadas, ou seja, impossibilitadas das diferenciações específicas na criação de unicidades identitárias categoriais. Ele nos provê de um exemplo simples e lógico, bem ao seu modo: se pensarmos que um homem difere de um barco, teremos necessariamente de admitir também sua indiferenciação. Desse modo, teríamos a constituição de uma grande unidade universal e uma impossibilidade de afirmação categórica sobre as unidades específicas, posto que a determinação de identidades esteja vedada: "Todas las cosas están confundidas. De suerte que nada existe que sea verdaderamente uno. El objeto de los discursos de estos filósofos es al parecer lo indeterminado" (Aristóteles, 1945, p. 86).

Para além da unidade, a dissolução da substância faz surgir o monismo, a "univocidade", a identidade absoluta do indeterminado, o universal do informe singular. Constitui-se assim, uma multiplicidade infindável de cadeias ilimitadas de acidentes a se relacionarem entre si na constituição do ser em uma imanência paradoxal de atributos (singularidades) nômades sem objeto ou sujeito. No entanto, antevendo tal fluidez, Aristóteles tenta mais um argumento contra este mundo fugidio:

Si se dice que todo es accidente, ya no hay genero primero, puesto que siempre el accidente designa un atributo de un sujeto. Es preciso, por lo tanto, que se prolongue hasta el infinito la cadena de los accidentes. Pero esto es imposible. Jamás hay más de dos accidentes ligados el uno al otro. El accidente no es nunca un accidente de un accidente, sino cuando estos accidentes son los accidentes de lo mismo sujeto. (Aristóteles, 1945, p. 85)

Vemos aí a um só tempo uma abertura e uma tentativa de fechamento de uma nova ontologia para além da reificação de substâncias em coisas. A abertura de uma ontologia complexa, sistêmica e processual, com cadeias infinitas de modos, ligando-se em arranjos processuais de coerências fugazes e afirmativas vê-se confrontada com uma condição lógica e metafísica imposta à existência: a necessidade essencial de uma essência necessária. Trata-se, no entanto, de uma petição de princípios, reafirmando os axiomas de uma ontologia substancial diante uma outra concepção que foge desta. Pois, se atributos não podem ser atributos por si, pela necessidade de pertencer a uma substância em torno da qual orbitam, é exatamente a possibilidade de um atributo de um outro atributo que permite a perspectiva monista e processual. Ao invés de dizermos que um atributo de um atributo é impossível por depender de um sujeito anterior, afirmamos aqui que é exatamente na operação de predicação de predicados sobre predicados que se constitui o sujeito.

Como nos alerta Nietzsche (1999), muitas das nossas concepções metafísicas de mundo estão fundadas sob a sedução da língua e sua gramática. Desse modo, o "penso, logo existo cartesiano", apresentado enquanto evidência autossustentável, é rachado em pedaços por Nietzsche, evidenciando que não se trata de um argumento-evidência, mas sim de uma construção plena de pressupostos complexos: que o pensar é algo específico e em si, e que o pensar pensa em algo que 
é "eu". Assim, além da presunção de isolar ao modo "pensar" em si, distinguido dos afetos e da sensação, por exemplo, vemos a conjugação na primeira pessoa, aliada ao formato gramatical da língua que divide a frase em sujeito e predicado, dando forma a um "eu" onde ocorre o pensar. "Mas não existe um tal substrato; não existe 'ser' por trás do fazer, do atuar, do devir; 'o agente' é uma ficção acrescentada à ação [sob sedução da linguagem]- a ação é tudo" (Nietzsche, 1998, p. 37), se tomarmos esta proposição do filósofo alemão de pensarmos uma língua, ou melhor, um mundo que ultrapassasse este binarismo agente-ação, onde para todo predicado há um sujeito da ação, algo que age, e adicionarmos a proposição deleuziana (Deleuze, 1975) de um mundo sempre a devir em verbos no infinitivo, temos aí uma nova ontologia para além das essências e substâncias. Obtemos, assim, a sanção para elaborar a alforria dos atributos perante as substâncias reificadas (sujeito, objeto, coisas, essências). Já não é mais necessário o pressuposto de uma substância para os acidentes, esses podem coadunar-se uns nos outros de modo ilimitado. Enquanto no exemplo Aristotélico (1945) não podíamos imaginar uma junção entre branco e músico que não se desse através da substância homem: homem - branco - músico, agora podemos tranquilamente imaginar a brancura e a musicalidade interagindo em formações para além do homem, constituindo músicas brancas, ou brancuras musicais, em uma cadeia ilimitada de variações. Agora é na relação, na conexão entre os elementos que veremos a fundamentação da ontologia do ser, e não mais em sua pretensa substância ou essência necessária.

E é neste mundo de atributos nômades, de linhas de forças em arranjos no porvir, que vemos a constituição do sujeito a partir de uma ação de reflexibilidade destes fugidios elementos. Quando a força age sobre si, quando o fora se dobra, quando o predicado predica a si mesmo, vemos a constituição de uma coerência autoorganizadora, vemos a constituição de uma vertigem autopoiética. Segundo Foucault, quando nos deparamos com o paradoxo do mentiroso, onde um homem afirma "estou mentindo", defrontamo-nos não simplesmente com o paradoxo da sentença e seu conteúdo, os quais não cessam de movimentar-se entre a veracidade ou falsidade da assertiva (já que, diante do conteúdo expresso de que o sujeito está mentindo, a veracidade da frase torna-a falsa e vice-versa). Para esse autor, a principal questão daí advinda é: "o sujeito que fala é o mesmo aquele pelo qual ele é falado" (Foucault, 2001, p. 219), problemática a qual será expressa em outra assertiva: "eu falo". Afinal, falar que se fala é visibilizar a circularidade na qual se assenta o sujeito que fala a si. Aqui, assim como no cogito cartesiano, aparentemente a assertiva dobra-se sobre si em sua tautologia de evi- dência não questionada de seus princípios, gerando uma interioridade autorreferida na qual nada escapa, tudo a reafirma, acalentando maternalmente uma interioridade identitária. Mas, tomando o "eu falo" em sua expressividade material mesma, na sua presentificação de um ser enunciado, e não segundo seu aspecto formal e lógico, vemos nessa a transitividade estilhaçada, de algo que não existe antes ou depois, porém, que simplesmente existe enquanto se afirma a força, enquanto é falado e atraído para o deserto exterior onde se perde do autor imaginado e representado, encontrando-se em uma rede impessoal de relações outras, desfazendo-se quando se cala, permanecendo silêncio do "zun-zum" anônimo. Fala-se aqui, e pronto, não aos sentidos e referentes. Dáse rouca voz, de grossas cordas vocalizadas, à delação do dissolver-se do sujeito por entre um mar de predicados. Rouca voz de caminho incerto e interferências múltiplas, onde o gaguejar ou a tosse ultrapassam a autoria na evidência do acaso, demonstrando que deus joga dados sim. Fala-se linguagem na expressividade crua do grito e do gemido, do resfolegar que se mostra carne e sangue, corpo em expressão, que ultrapassa a identidade da interioridade dos órgãos privados, antes mares-corpos em oscilações e (des)aparecimentos constantes e nada contrastantes. Lágrima e suor que salgam e odorizam o papel epidérmico, o qual já não adormece sob os tremores que lancinam lançando-lhe vivo ao exterior do deserto povoado: "em um silêncio que não é a intimidade de um segredo, mas o puro exterior onde as palavras se desenrolam infinitamente." (Foucault, 2001, p. 224). Não estamos diante de um mero jogo de contrários, pois aqui as diferenças unem-se em um movimento de por vir que revira os polos, abrindo-os às interferências do caos dos possíveis. Tampouco temos aqui a divisão entre sujeito e atributo que sustentava a tautologia autogeradora, a qual produzia identidades e interioridades sem jamais sair do lugar. Aqui, de fato, falamos de um deslocamento incessante: ultrapassamos a tautologia do sujeito que fala e é falado, para além do sujeito, em um emaranhado de falas anônimas e cotidianas a se agenciarem e (re)criarem. Vemos, portanto, a dissolução de uma determinada concepção de natureza atrelada a essências necessárias, em prol de uma definição mais aberta e fluida, menos constrangida a afirmações específicas. Uma natureza informe, indeterminada. Muito além e aquém das representações identitárias e dos movimentos autorreferentes fechados e absolutizados do em si reificado: natureza desnaturada.

Finda nossa desnaturalização da natureza entendida como essência necessária na qual cartografamos algumas linhas que constituem o pressuposto teórico operador dos conjuntos definidores de identidades essenciais para os sujeitos, grupos, entre outros, permitindo a construção de um mundo segmentado em "seres 
em si", não relacionais, os quais se relacionam apenas a partir da díade pré-formada sujeito-objeto. Com o desalinhar dessas linhas constituímos outro instrumento operacional o qual constitui um mundo em devir. Passamos agora a fazer frente a uma segunda acepção de natureza: em universo antropológico, entendida como um estado originário de inocência do homem.

\section{A potência do homem corrupto em Nietzsche: da desigualdade dos homens}

Tomando o Discurso sobre a origem e os fundamentos da desigualdade entre os homens de Rousseau $(1775 / 1978)$ como ponto de partida, temos um método e uma hipótese: a razão e o caráter harmônico do estado de natureza do homem, respectivamente. Nietzsche, no capítulo sobre historia natural da moral em seu Além do bem e do Mal (1886/1992), já de partida, coloca a questão da tirania da natureza consigo mesma e também em relação à razão, apontando a própria moral como movimento contraditório e natural. Entre um estado primitivo de natureza e um estado posterior da sociedade, Rousseau observa um longo desenvolvimento casual de corrupções do estado primeiro, desenvolvimento antinatural. Nietzsche, do contrário, encontra na passagem de um suposto estado natural para o estado da civilização um longo desenvolvimento necessário (o que não significa determinista) da própria natureza. $\mathrm{E}$ como últimos movimentos de suas reflexões acerca do caráter da natureza, de um lado Rousseau espera que a civilização reconheça as vantagens de uma vida conforme a natureza, de outro lado, Nietzsche quer do homem que ele (re)encontre uma natureza, mas não à maneira rousseauniana de um regresso civilizado, e sim como ascensão - o homem rumo a uma segunda natureza.

\section{Rousseau e a boa natureza hipotética do homem}

Um primeiro aspecto a ser notado é a ingenuidade filosófica de Rousseau quando toma a razão como um método do bem pensar, como se o entendimento tendesse espontaneamente às respostas verdadeiras, como se as deduções da razão fossem espontâneas. Ele simplesmente imagina subtrair do homem as "faculdades artificiais que ele só pôde adquirir por meio de progressos muito longos" e deparar-se então com o homem tal qual "deve ter saído das mãos da natureza". Rousseau não está, segundo aponta, preocupado em seu Discurso com "verdades históricas", e sim com "raciocínios hipotéticos e condicionais, mais apropriados a esclarecer a natureza das coisas do que mostrar a verdadeira origem" (Rousseau, 1775/1978, p. 236). Ele lança a hipótese seguinte: a do estado de natureza do homem, e a partir dela deduz suas consequências.

O que nos diz essa hipótese? Que o homem em seu estado de natureza é essencialmente harmônico, "um ser livre cujo coração está em paz e o corpo saudável", cujos modos de vida refletem "a ignorância dos vícios e a tranquilidade das paixões" e cuja imagem mostra um homem "fartando-se sob um carvalho, refrigerandose no primeiro riacho, encontrando seu leito ao pé da mesma árvore que lhe forneceu o repasto e, assim, satisfazendo a todas as suas necessidades" (Rousseau, $1775 / 1978$, p. 238). Ora, o que haveria de conter a explicação para nossa decadente saída desse estado de harmonia - suposto, tal como aceito por Rousseau - o qual, se não houvesse causas extrínsecas a ele, teria o homem continuado nessa condição?

Rousseau atribui esse êxodo do paraíso a "um concurso fortuito de causas estranhas, que nunca poderiam surgir" (Rousseau, 1775/1978, p. 258), mas o que nos importa saber é que esse concurso de causas forma as condições para o surgimento do estado social, esse sim, o demônio que instaura a verdadeira desigualdade entre os homens. Para Rousseau, as desigualdades naturais, não obstante serem quase nulas, não implicam a miserabilidade da existência. Essa deve ser entendida como o conjunto das consequências de uma espécie de ato civilizatório, antinatural, ato primevo das desigualdades sociais.

Em suma, o que não aparece no Discurso de Rousseau é a possibilidade de um artifício intrinsecamente natural, a possibilidade de que a imaculada natureza seja geneticamente corrupta. É esse salto no escuro que marca a passagem da primeira para a segunda parte do discurso, que já começa com a afirmação de que "o verdadeiro fundador da sociedade civil foi o primeiro que, tendo cercado um terreno, lembrou-se de dizer isto é meu e encontrou pessoas suficientemente simples para acreditá-lo" (Rousseau, 1775/1978, p. 259).

Rousseau demarca, claramente, ao longo de seu $\underline{\text { Discurso, }}$, seus dois grandes continentes de análise, os estados de natureza e de sociedade, e visa ao cabo desse trabalho lucrar com a demonstração de que o segundo estado é exatamente a corrupção do primeiro, mas esquece justamente de nos mostrar como atravessa de um a outro desses continentes. É justamente essa passagem, salva-guarda da corrupção da própria natureza, que veremos ao abordar o texto nietzschiano.

\section{Nietzsche e a corrupção da natureza: o homem como grande doença e grande promessa}

Nietzsche dá início à sua segunda dissertação para uma genealogia da moral com a seguinte colocação 
interrogativa: "Criar um animal que pode fazer pro-

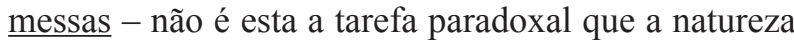
se impôs com relação ao homem? Não é este o verdadeiro problema do homem?" (Nietzsche, 1998, p. 49). Sublinhemos o que mais nos importa nessa passagem, o fato de que a tarefa paradoxal, segundo Nietzsche, é uma imposição da própria natureza a si mesma. Ao contrário de Rousseau, o filósofo alemão não dispensa um "método histórico",

tanto mais porque vai de encontro ao gosto e aos instintos agora dominantes, que antes se conciliariam até mesmo com a contingência absoluta [completamente condizente com a hipótese roussaueniana], com a mecânica absurdidade de todo acontecer, do que com uma teoria da vontade de poder operante em todo acontecer. (Nietzsche, 1998, p. 67)

Essa é a grande diferença interpretativa de nossos filósofos, a suposição de uma espécie de princípio imanente à natureza capaz de justificar toda sorte de rupturas, acasos, saltos e corrupções da própria natureza. Que princípio é esse? A vontade de poder, princípio sem o qual "se desconhece a essência da vida", "não se percebe a primazia fundamental das forças espontâneas, agressivas, expansivas, criadoras de formas, interpretações e direções" (Nietzsche, 1998, p. 67). A livre necessidade dessas forças criadoras de formas, esse é, se o reivindicamos, o verdadeiro estado de natureza para Nietzsche. E a sociedade? Somente mais um destes frutos que da própria natureza brotam; a natureza nunca fora corrompida, o estado de natureza nunca fora uma pobre vítima, nunca fora justo, na medida em que “essencialmente, isto é, em suas funções básicas, a vida atua ofendendo, violentando, explorando, destruindo, não podendo sequer ser concebida sem esse caráter" (Nietzsche, 1998, p. 65), e a gênese da sociedade não poderia, segundo Nietzsche, ser concebida de outro modo - 'Utilizei a palavra 'Estado', está claro a que me refiro ... uma raça de conquistadores e senhores, que ... lança suas garras terríveis sobre uma população talvez imensamente superior em número, mas ainda informe e nômade" (Nietzsche, 1998, p. 74). Assim, a sociedade, como toda formação e organização que se possa imaginar, é vontade de poder e nada mais, ou seja, nada está além desta física, pode-se dizer provocativamente, natural. Para Nietzsche, se nos entendemos até o momento, ou o homem ainda vive em seu estado de natureza ou tal estado nunca existiu. O homem é mais um caso da natureza corrompida em si e por si mesma, natureza é corrupção e sem isso é nada mais que uma ideia morta, um consolo sentimental ou hipótese fracassada.

Com Nietzsche, a natureza, antes de ser um estado prototípico e antagônico à sociedade, a la Rousseau, é um processo interminável de metamorfoses e resoluções parciais, que até o presente momento de nossa história nos brindou com duas grandes possibilidades: o homem como doença e o homem como uma grande promessa. Num caso, "foi introduzida a maior e mais sinistra doença, do qual até hoje não se curou a humanidade, o sofrimento do homem com o homem, consigo: como resultado de uma violenta separação de seu passado animal" (Nietzsche, 1998, p. 73). No outro, o homem como um espetáculo que "desperta um interesse, uma tensão, uma esperança, quase uma certeza, como se com ele algo se anunciasse, algo se preparasse, como se o homem não fosse uma meta, mas apenas um caminho, um episódio, uma ponte, uma grande promessa..." (Nietzsche, 1998, p. 74).

De tudo que foi dito até aqui, o que mais nos interessa é menos a oposição entre Nietzsche e Rousseau

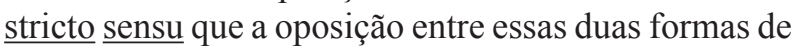
ver e interpretar a natureza, bem como as consequências inevitáveis que essa oposição traz para o problema do homem. Há, ao que parece, seguindo o páreo entre Rousseau e Nietzsche, uma diferença abismal entre as tarefas que nos esperam, entre um arrogante melhoramento e reforma da humanidade e uma inocente aposta na humanidade, no sentido de que a superação de uma determinada estrutura das forças sociais é imanente ao próprio devir dessas forças e a crença nesse devir sem encerrá-lo num paraíso perdido é, talvez, a melhor das apostas: uma diferença entre negar e afirmar as coisas da vida e do homem.

\section{Corrupção e simulacros: natureza desumana}

Nossos esforços até o momento se concentraram num movimento de resistência: resistimos acima de tudo a ver na natureza uma benevolência imaculada, a pureza substancial em Aristóteles e a doçura selvagem em Rousseau. Que natureza é essa que reflete a especulação de dois pensadores tão distantes no tempo? Por que a natureza foi concebida especulativamente? Especular é o caráter que nos remete ao espelho, neste caso, ao espelho da razão; esses pensadores encontraram a natureza olhando para si mesmos e sequer puderam se encontrar, pois inverteram a própria imagem e acreditaram na ideia de si mesmos. Se Aristóteles não tivesse sido tão convicto da virtude como medianidade, e se Rousseau tivesse estado de fato em meio aos selvagens, talvez tivessem visto a natureza com outros olhos: sobra-lhes ratio e falta-lhes sensíveis, falta a sensibilidade do concreto pouco afeito a simetrias abstratas. O homem cansado de si, ou seja, da natureza no homem, prefere pintá-la como o ser benevolente e imaculado. Em Aristóteles, certamente, a natureza como essência, considerada metafisicamente, é indiferente à benevolência, mas é igualmente uma projeção humana, demasiado humana, como 
diria o filósofo alemão. Ela é a origem sem mácula, sem acidentes, sem quebrantos, a negação de tudo o que nós, seres humanos, passamos do primeiro ao último dia. A natureza desumanizada que afirmamos é a natureza sem o rosto triste de nossos ideais, é o contentamento com tudo aquilo que passa, morre, quebra, definha, sucumbe: a natureza. Elogiamos as grandes farsas e corrupções da natureza, os seus intermináveis processos, repetições e novidades, porque nós somos mais um truque dessa mesma natureza, sem origem e sem fim, aquém do ato criador e além do juízo final. Se existe deus, ele é spinozista: Deus sive Natura (Deus ou Natureza).

\section{Sobre plantas e homens: natureza desnaturada}

Aristóteles, ao falar de Protágoras e dos demais Sofistas na Metafísica, dá um toque de humor irônico à sua arguição, tornando-a algo mais ferina aos nossos ouvidos. Participando de uma velha tradição de desvalidar proposições filosóficas com a evidenciação de sua aparente incompatibilidade com uma vida prática, nosso sagaz filósofo de Estagira irá dizer que, aos que afirmavam a paradoxal multiplicidade ontológica dos sentidos, negando o princípio de não contradição e às próprias essências, restava o estado vegetativo, pois nada mais poderiam fazer em um mundo sem uma verdade. "Si todos los hombres dicen igualmente la falsedad y la verdad, tales seres no pueden ni articular un sonido, ni discurrir, porque dicen al mismo tiempo una cosa y no la dicen. ... ¿en qué se diferencian de las plantas?" (Aristóteles, 1945, pp.87-88).

Nosso movimento diante desta pecha seria imediatamente afirmarmos que o conceito de nada não é o nada de conceito, e que a queda das diretrizes abstratas e essenciais antes produz uma multiplicidade ilimitada de sentidos, e não apenas o devoramento completo desse, ainda que o non sense seja parte do paradoxo e sua fome nada fácil (Deleuze, 1975). Mas, antes de nos opormos, pensemos o que é afinal uma planta para Aristóteles? O que nos estaria atribuindo essa acusação?

No De anima (Aristóteles, 2006), Aristóteles irá discorrer sobre as diversas almas que habitam e animam os corpos, os diversos princípios vitais de ação, movimento, mudança, etc. que agem sobre si nas coisas. Desse modo, Aristóteles nos apresenta o princípio mínimo, aquilo que a todos os seres pertence, sendo exatamente a característica própria das plantas: a vida nutritiva. Uma potência vegetativa universal dos seres vivos, despossuída de sujeito e intenção, reduzindose à mera potencia vital impessoal. Algo como nossa contemporânea acepção médica de vida vegetativa, ou seja, vida aquém e para além do cérebro, vida sem sujeito e consciência.
Enquanto em Aristóteles a vida vegetativa é aquilo que pode ser atribuído a todo sujeito (generalização), posto que seja atributo desse, aqui diremos que esta vida não pertence a qualquer sujeito, posto que não é posse, nem passível de generalização, mas antes uma vida imanente e impessoal. Revertemos assim a injúria em jurisprudência, tomando de assalto a infâmia para torná-la o princípio que inflama e justifica nossa concepção de natureza desumana. Somos plantas sim, pois o que constituíra afirmativamente nosso conceito de natura é exatamente esta vida nutritiva, impessoal, para além de sujeito, objeto, consciência, essência necessária, substância, entre outras várias entidades abstratas de uma metafísica transcendente. Somos plantas ao modo que nos fala Simondon (2003), somos saltos entre os químicos do solo e a radiação cósmica dos raios solares, somos um risco que atravessa e relaciona, um gesto que afeta e cria.

O operador ontológico deixa de ser o "é" em sua individualização igualitária, que divide o mundo em sujeito substancial e atributos sensíveis, e passa a ser o "e", desarticulando o ser ao transpassá-lo por agenciamento, tornando-o arranjo de forças sem agente ou unidade totalizante. $\mathrm{O}$ “é", enquanto elemento conjuntivo ontológico, atribui uma substância, essência necessária, ou equivalência identitária aos seres diversos, erigindo categorias que submetem os modos de ser. Já através do elemento conjuntivo ontológico "e", operamos uma bricolagem existencial não reificada, constituída nas relações imanentes entre as forças: diversas cadeias de acidentes conectadas em um mundo para além do binário sujeito-predicado dando univocidade a essa expressão da diferença.

Partindo de que vida é imanência (Agamben, 2000) e imanência é univocidade (Badiou, 2000), e afirmando que a natureza é aqui concebida enquanto esta ilimitada variação do ser sobre si, aquém de transcendências, podemos afirmar uma estreita e complexa relação entre esses termos, afirmando, por fim, que a natureza é a imanência operando univocidade pela criação constante de um território comum de encontros parciais. Uma natureza em por vir desejante, desubstancializada, a afirmar diversos mundos diversos. Vida, natureza e univocidade como a ação das forças sobre si na criação dos mundos e afirmação do ser.

A natureza não se apresenta então como uma unidade das coisas nem como uma totalidade do que há, conjunto dos conjuntos terrenos, e, tampouco, como uma homogeneidade do ser ou uma ordem dada, forma primeira das substâncias e do homem. Constitui ainda, no entanto, algo comum que entrelaça aos acontecimentos no mundo: um plano comum dos encontros, entendendo por comum não o Mesmo, não relações de igualdade e equivalência, mas antes a ilimitada possibilidade de mútua afetação, o comum da possibilidade de encontros. 
Não se trata de algo, uma propriedade ou atributo de um fluxo, que atravessa todos luzindo uma igualdade essencial por sobre a translucidez dos demais fluxos parciais. Trata-se não de uma linha que atravessa a tudo e todos, até por que tudo e todos não são passíveis de apreensão, mas sim de um complexo de relações parciais e fugidias, constituindo um espaço de afetação comum não linear e imanente. Trata-se de uma paradoxal natureza paradoxal que une aquém da unidade aos, antes opostos, caos e ordem: nem ordem benevolente a ser resguardada, nem caos selvagem a ser polido, a natureza é criação, é imanência criadora de imanência. É construção de si, poiesis, gravidez incessante de mundos vários, e não dádiva dada, divina ou mundana, a ser descoberta pelo pároco ou laico especialista. Natureza é invenção imanente da imanência: "O universo é mais Shakeperiano do que Newtoniano" (Morin, 2002, p. 445).

A natureza nessa concepção não se trata de uma objetividade dócil e determinada, mas antes se constitui como um paradoxal princípio de indeterminação virtual. Assim, enquanto causa imanente a si, vemos a natureza como processo, ação, relação, gesto, e não obra ou ordem representacional do mundo. Desviamos-nos um pouco, assim, da estrutura dual que ordena o mundo segundo uma relação conflitiva de oposição entre natureza e não-natureza, erigindo uma série de pares, os quais estriam simetricamente nosso mundo ocidental: natura versus cultura, natural versus artificial, natural versus contingente, natural versus inventado, animal versus homem, homem versus deus.

Há que se pensar a natureza como criadora inventiva que ultrapassa a reprodução do mesmo no devir de novos modos, devolver-lhe a poiesis que fora outorgada somente aos poetas, alijando sua mais sedutora face dos cientistas que se deitam com ela nos laboratórios e campos exploratórios, os quais daí obtiveram uma série ilimitada de corpos limitados, isolados em si em uma natureza feita de substâncias particulares generalizáveis. Tomada de poesia, passa a ter a complexidade e a heterogeneidade enquanto seus princípios e base mais simples, e a relação ilimitada (que inclui a não relação) é agora sua maior e menor unidade possível.

Falamos aqui, deste modo, de uma natureza desnaturada, não somente no sentido de uma natureza não essencial, uma natureza sem natureza substancial ou formal, sem fixidez de ser, intempestiva em suas variações. Mas também de uma natureza desnaturada no sentido de possuir uma crueldade desumana, um sentido para além do humano e suas abstrações sobre uma natureza enquanto útero primeirúltimo a ser preservado ou selvageria a ser domada. Assim, vemos uma natura que não se presta à fixidez dos mandamentos do dever. O apego ao dever, o moralismo, depende de uma transcendência do natural que lhe sustente os tentos. Há que se encontrar um ponto abstrato, insensível e confiável para além da natureza, posto que esta rapariga da vida não serve de mão gentil. O dever deve ser aquém de corrupções que lhe variem os sensos e aticem sensibilidades. Na natureza e sua sensual sensorialidade movediça, qualquer edifício moral é devorado por sua paradoxal variação impessoal imanente a corromper transcendências, constituindo-se um monstro do pecado, meretriz generosa a corromper o bem $^{3}$. Uma natureza que é só desmesuras do mundo para com o homem e sua polidez demasiado humana.

\section{Notas}

1 Segundo Aristóteles em sua Metafísica (1945), a unidade de natureza pode se dar basicamente de duas formas, a unidade de número e a unidade de gênero. A unidade de número trata dos entes discretos, entes indivisíveis tomados enquanto unidades distintas, descontínuas. Já a unidade de gênero se opera por analogia, relações que comungam um só ser, formando conjuntos de entes segundo um ser, uma substância segunda. Vemos assim, portanto, uma unidade fundada em uma substância primeira ou substrato e outra fundada em uma substância segunda ou forma (telos). Sendo ambas, no entanto, essências necessárias: natureza.

2 Entende-se com isso a afirmação de Deleuze em Diferença e Repetição (1988) de que em Aristóteles a diferença opera como nos jogos de adivinhação, onde a pergunta "qual a diferença entre X e Y", pode ser tranquilamente substituída para "o que X e Y têm em comum". "En las definiciones se da el nombre de género a la noción fundamental y esencial, cuyas cualidades son las diferencias" (Aristóteles, 1945, p.129).

3 "toda vez que tentamos repetir segundo a natureza, como seres da natureza (repetição de um prazer, de um passado, de uma paixão), lança-nos numa tentativa demoníaca, desde já maldita, que só tem como saída o desespero ou o tédio." (Deleuze, 1988, p. 26).

\section{Referências}

Agamben, G. (2000). A imanência absoluta. In E. Alliez (Org.), Gilles Deleuze- uma vida filosófica (pp. 169-192). São Paulo: Ed. 34.

Aristoteles. (1945). Metafísica. Buenos Aires: Ed. Espasa. Aristoteles. (1985). Organon. Lisboa: Guimarães Editores. Aristoteles. (2006). De anima. São Paulo: Ed. 34.

Badiou, A. (2000). A vida como nome do ser. In E. Alliez (Org.), Gilles Deleuze- uma vida filosófica (pp. 159-160). São Paulo: ed. 34 .

Deleuze, G. (1975). Lógica do sentido. São Paulo: Ed. Perspectiva.

Deleuze, G. (1988). Diferença e repetição. Rio de Janeiro: Graal.

Foucault, M. (2001). O pensamento do exterior. In M. B. da Mota (Org.), Ditos \& escritos (Vol. III, pp. 219-242). Rio de Janeiro: Forense Universitária.

Hardt, M. \& Negri, A. (2004). Império. Rio de Janeiro: Ed. Record. 
Morin, E. (2002). O método vol. 1 - a natureza da natureza. Porto Alegre: Ed. Sulina.

Nietzsche, F. (1992). Além do bem e do mal: prelúdio a uma filosofia do futuro. São Paulo: Companhia das Letras. (Original publicado em 1886)

Nietzsche, F. (1998). Genealogia da moral: uma polêmica. São Paulo: Companhia das Letras.

Nietzsche, F. (1999). Obras incompletas (Coleção Os Pensadores). Nova Cultural: São Paulo.

Rousseau, J-J. (1978). Discurso sobre a origem e os fundamentos da desigualdade entre os homens (Coleção Os Pensadores). São Paulo: Abril Cultural. (Original publicado em 1775)

Simondon, G. (2003). A gênese do indivíduo. In P. Pelbart \& R. da Costa (Orgs.), Cadernos de subjetividade: o reencantamento do concreto (pp. 97-117). São Paulo: Editora HUCITEC EDUC.

Recebido em: 27/11/2008

Revisão em: 28/12/2009

Aceite final em: 07/07/2010
Luis Artur Costa é Doutorando no PGIE UFRGS, Mestre em Psicologia Social e Institucional pela Universidade Federal do Rio Grande do Sul. Bolsista CAPES. Email: lartur@cpovo.net

Daniel Dutra é Mestrando do Programa de pós-graduação em Psicologia Social e Institucional da Universidade Federal do Rio Grande do Sul. Email: ddtpsi@yahoo.com.br

Tania Mara Galli Fonseca é Professora dos Programas de pós-graduação em Psicologia Social e Institucional e em Infomática na Educação da Universidade Federal do Rio Grande do Sul. Endereço: Rua Ramiro Barcelos, 2600. Sala 13. Porto Alegre/RS. CEP 90035-003. Email: tfonseca@via-rs.net

\section{Como citar:}

Costa, L. A., Dutra, D., \& Fonseca, T. M. G. (2011). Natureza desumana: desmesuras do mundo ao homem. Psicologia \& Sociedade, 23(1), 5-14. 